\title{
Development of Novel Activated Carbon-Based Adsorbents for Control of Mercury Emissions From Coal-Fired Power Plants
}

\author{
Semi-Annual Report \\ March 1 - August 31, 1997 \\ By
Radisav D. Vidic
}

Work Performed Under Contract No.: DE-FG22-96PC96212

\author{
For \\ U.S. Department of Energy \\ Office of Fossil Energy \\ Federal Energy Technology Center \\ P.O. Box 880 \\ Morgantown, West Virginia 26507-0880
}

By

Department of Civil and Environmental Engineering

University of Pittsburgh

Pittsburgh, Pennsylvania 15261-2294 


\section{Disclaimer}

This report was prepared as an account of work sponsored by an agency of the United States Government. Neither the United States Government nor any agency thereof, nor any of their employees, makes any warranty, express or implied, or assumes any legal liability or responsibility for the accuracy, completeness, or usefulness of any information, apparatus, product, or process disclosed, or represents that its use would not infringe privately owned rights. Reference herein to any specific commercial product, process, or service by trade

name, trademark, manufacturer, or otherwise does not necessarily constitute or imply its endorsement, recommendation, or favoring by the United States Government or any agency thereof. The views and opinions of authors expressed herein do not necessarily state or reflect those of the United States Government or any agency thereof. 


\title{
DEVELOPMENT OF NOVEL ACTIVATED CARBON-BASED ADSORBENTS FOR CONTROL OF MERCURY EMISSIONS FROM COAL-FIRED POWER PLANTS
}

\author{
Semi-Annual Technical Report \\ Reporting Period: 03/01/1997 through 08/31/1997 \\ Author: Radisav D. Vidic \\ Report Issue Date: 09/08/1997 \\ DE-FG22-96PC96212 --02 \\ Department of Civil and Environmental Engineering \\ University of Pittsburgh \\ Pittsburgh, PA 15261-2294
}




\begin{abstract}
The overall objective of this study is to evaluate pertinent design and operational parameters that would enable successful application of activated carbon adsorption for the reduction of mercury emissions from coal-fired power plants.

The study will evaluate the most suitable impregnate such as sulfur, chloride and other chelating agents for its ability to enhance the adsorptive capacity of activated carbon for mercury vapor under various process conditions. The main process variables to be evaluated include temperature, mercury concentration and speciation, relative humidity, oxygen content, and presence of $\mathrm{SO}_{2}$ and $\mathrm{NO}_{\mathrm{x}}$ in the flue gas. The optimal amount of impregnate for each of these carbons will be determined based on the exhibited performance.

Another important parameter which governs the applicability of adsorption technology for the flue gas clean up is the rate at which vapor phase mercury is being removed from the flue gas by activated carbon. Therefore, the second part of this study will evaluate the adsorption kinetics using the impregnated activated carbons listed above. The rate of mercury uptake will also be evaluated under the process conditions that are representative of coal-fired power plants.

Concerned with the ability of the adsorbed mercury to migrate back into the environment once saturated adsorbent is removed from the system, the study will also focus on the mercury desorption rate as a function of the type of impregnate, loading conditions, and the time of contact prior to disposal.
\end{abstract}


TABLE OF CONTENTS

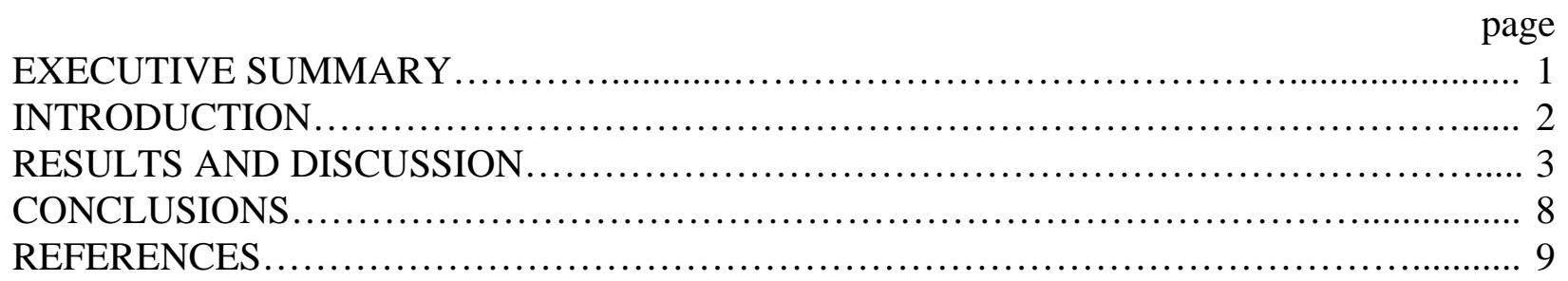




\section{EXECUTIVE SUMMARY}

The objective of this study during the second six-month period was to optimize impregnation procedure for fixed-bed application of sulfur impregnated sorbents for mercury control. The sulfur to carbon ratio (SCR) was introduced as a new control parameter for the impregnation procedure of activated carbons. Some coal samples and regenerated activated carbon were also studied as potential substrates to be impregnated with sulfur. Physical characteristics of these carbons affecting the mercury uptake capacity were further investigated by examining the specific surface area and pore size distribution of carbon particles. The effect of oxygen presence in the carrier gas on mercury uptake was also evaluated during this period of study.

The newly derived adsorbents were named based on the starting material, SCR and impregnation temperature. For example, BPL-S-4/1-600 denotes a BPL carbon that was impregnated with sulfur at SCR 4:1 and temperature of $600{ }^{\circ} \mathrm{C}$. Previous study has shown that higher impregnation temperature can significantly enhance mercury removal capacity of sulfur-impregnated activated carbons. However, current study of SCR shows that mercury removal capacity does not vary drastically when sulfur to carbon ratio changes from 4:1 to 1:2.

Both virgin coal and sulfur-impregnated coal samples have extremely low mercury uptake capacity. Sulfur-impregnated regenerated activated carbons showed much higher mercury uptake capacity that is comparable to those of BPL impregnated carbons.

BPL-S-4/1-600 adsorbent was used to study the oxygen effect on mercury uptake. Small increase in mercury uptake was observed when 3\% of oxygen was introduced into the carrier gas. However, higher mercury uptake capacity was measured when oxygen concentration was increased from $6 \%$ to $9 \%$. It was concluded that this improvement was due to the formation of mercury oxide that is catalyzed by activated carbon surface.

Bonding between sulfur and carbon, as determined by thermogravimetric analysis (TGA), was dependent on the impregnation procedure. Higher impregnation temperatures promote more uniform distribution of low molecular weight sulfur allotropes on the carbon surface.

Pore size distribution study on these adsorbents revealed that high impregnation temperature resulted in larger pore openings in the inner structure of the carbons. Consequently, adsorbents prepared at high impregnation temperatures performed better than those prepared at low temperatures. 


\section{INTRODUCTION}

Environmental control agencies and researchers have become increasingly concerned with mobilization of trace elements to the environment from fossil fuel burning. Mercury is a trace element of particular concern since, during coal combustion, most of the mercury present in coal is transferred into vapor phase due to its high volatility, while currently used pollution abatement technologies are not capable of controlling gas-phase mercury emissions. Once discharged into the atmosphere, mercury persists in the environment and creates long-term contamination problems. Furthermore, well documented food chain transport and bio-accumulation of mercury require strict control of mercury emissions from coal-fired power plants (1). Activated carbon adsorption is a unit process that offers great promise for achieving high quality air emissions with respect to mercury and other trace elements that might be present in gases emitted from coal-fired power plants. Granular activated carbon (GAC) used in packed bed configuration offers potential for the recovery of mercury from gas streams, and desirable handling properties with respect to final disposal of mercury (2).

The proposed research work will evaluate pertinent design and operational parameters that would enable successful application of this efficient technology for mercury control. The key tasks of this study are: 1) optimize the type and percent impregnate as well as the impregnation procedure that would provide the most significant enhancement of activated carbon capacity for vapor phase mercury, 2) establish the dependency of activated carbon adsorptive capacity on temperature and mercury concentration; 3) evaluate possible interference of other compounds in the vapor phase with mercury removal mechanism; and 4) develop scale-up procedure for correlating the performance of laboratory and pilot-scale granular activated carbon adsorbers. 


\section{RESULTS AND DISCUSSION}

\section{Materials and Methods}

A commercially available bituminous coal-based activated carbon (BPL) was supplied by the manufacturer (Calgon Carbon Corporation, Pittsburgh, PA) in 4×10 U.S. mesh size. HGR, which is a sulfur-impregnated activated carbon derived from BPL in $4 \times 10$ and $12 \times 30$ U.S. mesh size, and React-A, which is a regenerated activated carbon in $4 \times 10$ U.S. mesh size, were also provided by the same manufacturer. BPL, HGR and React-A carbons were ground into $60 \times 80$ mesh size having a geometric mean diameter of $0.021 \mathrm{~cm}$. A sample of Upper Freeport (UFP) coal (FETC, Pittsburgh, PA) was also used in this study. This coal sample contained mainly fine particles, and was sieved to $170 \times 230$ U.S. mesh size. In order to avoid changes due to exposure to oxygen, $\mathrm{CO}_{2}$ and moisture, all adsorbents were kept in a desiccator under vacuum prior to use.

Figure 1 shows the configuration of the experimental system used for impregnating elemental sulfur onto the solid substrate. High purity $(99.99+\%)$ elemental sulfur flakes (Aldrich Chemical Company, Milwaukee, WI) were used in the impregnation process. A 19-inch long, 1 inch outer diameter, open-ended, hollow quartz tube was used as a holder in the tube furnace (Lindberg Type 55035, Watertown, WI). Two rubber stoppers were used to seal the system.

Prior to the impregnation process, high purity $\mathrm{N}_{2}$ (Praxair, Westlake, $\mathrm{OH}$ ) was purged through the empty quartz tube at a flow rate of $1.0 \mathrm{~L} / \mathrm{min}$ for 30 minutes in order to remove most of the oxygen. 2 grams of solid substrate were placed evenly in a ceramic boat and a predetermined amount of sulfur was placed in another ceramic boat. The nitrogen gas flow rate was reduced to $60 \mathrm{~mL} / \mathrm{min}$ and the upstream rubber stopper on the quartz tube was removed to place the carboncontaining boat followed by the sulfur-containing boat into the tube. The system was quickly closed and nitrogen gas was passed through the quartz tube for one hour at room temperature to completely remove traces of oxygen from the tube and create inert atmosphere in the tube. The furnace temperature was adjusted to the required setting and maintained for two hours while continuously purging nitrogen gas through the system. After the furnace cooled back to room temperature, the carbon-containing boat was transferred to a desiccator for future use. The designation of newly derived sorbents was based on the starting material, sulfur to carbon ratio (SCR), and impregnation temperature. For example, BPL-S-4/1-600 denotes a BPL carbon that was impregnated with sulfur at SCR of $4: 1$ and temperature of $600{ }^{\circ} \mathrm{C}$. The same sulfur impregnation procedure was also used when impregnating React-A and UFP coal.

A fixed bed reactor column was designed and installed for the vapor phase mercury removal test. The layout of the experimental setup and description of the procedure can be found elsewhere (3). The carrier gas for the experiments was pure nitrogen. Proper oxygen and nitrogen mixture was prepared as a carrier gas only for the study designed to evaluate oxygen effects on mercury uptake.

The sulfur content for each carbon was examined by a Leco Model SC 132 sulfur determinator (Leco Corporation, St. Joseph, MI). The specific surface area and pore size distribution for these 
samples were measured by an Orr Surface-Area Pore-Volume Analyzer Model 2100 (Micromeritics Instrument Corporation, Atlanta, GA) using a nitrogen BET method.

In order to obtain reliable and reproducible data, the following quality control and quality assurance procedures have been used throughout each experimental step: 1) the AAS readings vs. mercury concentration was calibrated based on EPA Method 29 (a linear relationship between absorbance and mercury concentration was always established); 2) the effluent gas from each column run was periodically collected in an impinger solution, and the amount of total mercury in the impinger solution was compared to gas phase elemental mercury measurements; 4) the spent carbon was burned in a combustor and the effluent gas from that combustor was collected in impingers to verify the mass balance on mercury.

\section{Results and Discussion}

\subsection{Effect of sulfur to carbon ratio (SCR) on mercury uptake}

Figure 2 illustrates the mercury removal efficiency for the BPL-S series with different SCR. When SCR changed from 4:1 to 2:1, the capacity for mercury removal did not experience a significant decrease. Major loss in capacity was observed when SCR was reduced from 2:1 to 1:1. As shown in Figure 2, both BPL-S-4/1-600 and BPL-S-2/1-600 exhibited high capacity for mercury uptake. However, the capacity for mercury uptake of BPL-S-1/1-600 is only $60 \%$ compared to the previous two, and BPL-S-1/2-600 demonstrated even lower capacity.

\subsection{Mercury uptake by coal samples and regenerated activated carbon}

Figure 3 compares mercury uptake capacity of coal samples and HGR. From the scale of the ordinate, it is clear that the uptake capacity for these three samples is much lower than the capacity of BPL-S series. The amount of mercury adsorbed by HGR was only $44 \mu \mathrm{g} \mathrm{Hg} / \mathrm{g}$ carbon. Mercury uptake capacity of UFP-4/1-600 was only $4 \mu \mathrm{g} \mathrm{Hg} / \mathrm{g}$ coal, while the uptake capacity of UFP was negligible (less than $2 \mu \mathrm{g} \mathrm{Hg} / \mathrm{g}$ coal).

Adsorption capacity of React-A-4/1-600 was compared to the performance of BPL-S-4/1-600 in Figure 4. As is apparent from this figure, React-A-4/1-600 demonstrated very similar performance for mercury uptake to that of BPL-S-4/1-600, yielding the overall mercury uptake capacity of $1900 \mu \mathrm{g} / \mathrm{g}$ carbon.

\subsection{BET, Sulfur Content and TGA analyses of the novel adsorbents}

Depending on the ambient temperature, sulfur exists in a variety of allotropes. At high temperature, predominant forms are short chain structures that have more terminal active sulfur atoms which are responsible for the reactivity of the sulfur. At low temperature, long chain or ring forms comprise the main allotropes of sulfur. Consequently, less active terminal sulfur atoms are available at low temperature. 
Large specific surface area within carbon particles offers more active sites for mercury and sulfur reaction. Consequently, carbons prepared at high temperature that also have high specific surface area exhibit better performance in the uptake of elemental mercury vapors.

Table 1 summarized the sulfur content and specific surface area for each adsorbent used in this study. For the BPL-S series, the actual sulfur content decreases from $10.04 \%$ to $7.11 \%$ as the SCR varies from 4:1 to $1: 2$. Since the BPL-S series was prepared at the same temperature $(600$ ${ }^{\circ} \mathrm{C}$ ), the decrease of sulfur content indicated the decrease of the amount of active sulfur terminal atoms. Therefore, the mercury uptake capacity would become smaller when SCR changed from $4: 1$ to $1: 2$.

Table 1. Sulfur Content and Surface Area of Sorbents

\begin{tabular}{|c|c|c|}
\hline Sample Type & Sulfur Content, wt $\%$ & Specific Surface Area, $\mathrm{m}^{2} / \mathrm{g}\left(\mathrm{yd}^{2} / \mathrm{lb}\right)$ \\
\hline BPL-S-4/1-600 & 10.04 & $823.7\left(4.470 \times 10^{5}\right)$ \\
\hline BPL-S-2/1-600 & 9.12 & $897.6\left(4.871 \times 10^{5}\right)$ \\
\hline BPL-S-1/1-600 & 8.31 & $860.6\left(4.670 \times 10^{5}\right)$ \\
\hline BPL-S-1/2-600 & 7.11 & $859.0\left(4.662 \times 10^{5}\right)$ \\
\hline BPL & 0.7 & $1026\left(5.568 \times 10^{5}\right)$ \\
\hline BPL (heated at $\left.600{ }^{\circ} \mathrm{C}\right)$ & 0.45 & $989.5\left(5.370 \times 10^{5}\right)$ \\
\hline HGR & 9.66 & $782.6\left(4.247 \times 10^{5}\right)$ \\
\hline React-A-4/1-600 & 8.56 & $826.2\left(4.484 \times 10^{5}\right)$ \\
\hline UFP & 1.47 & $45.0\left(2.442 \times 10^{4}\right)$ \\
\hline UFP-4/1-600 & 4.65 & $20.5\left(1.113 \times 10^{4}\right)$ \\
\hline
\end{tabular}

React-A-4/1-600 showed high mercury removal capacity (1850 $\mu \mathrm{g} \mathrm{Hg} / \mathrm{g}$ carbon) due to its $8.56 \%$ sulfur content and high specific surface area. On the other hand, UFP-4/1-600 had low sulfur content and extremely small specific surface area. As a result, its mercury uptake capacity was negligible (4 $\mu \mathrm{g} \mathrm{Hg} / \mathrm{g}$ coal) compared to the BPL-S series and React-A-4/1-600.

Because HGR carbon was prepared at low temperature (between 150 and $200{ }^{\circ} \mathrm{C}$ ), it has less active terminal sulfur atoms than the BPL-S series. Also, its specific surface area is about $20 \%$ less than that of the BPL-S series. Hence, it showed lower mercury removal capacity $(44 \mu \mathrm{g} \mathrm{Hg} / \mathrm{g}$ carbon) than BPL-S series.

Liquid nitrogen desorption method was used to measure the pore size distribution of HGR and BPL and its derivatives. All pore size distribution measurements on BPL-S-4/1 and BPL-S-600 series are summarized in Figures 5 and 6, respectively. As can be seen from Figure 5, the undersized pores (radius less than 20 è) and the oversized pores (radius greater than 180 è) consist only a small portion of total pores for all carbons used in this study. The major differences among these carbons can be found in the distribution of 40 to 100 è pores. In order to study the temperature effect on pore size distribution, virgin BPL carbon was heated at $600{ }^{\circ} \mathrm{C}$ for 2 hours. As can be seen in Figure 5, heated BPL has larger volume of pores in the range 40 to 
100 è than the original substrate (BPL). Apparently, $600{ }^{\circ} \mathrm{C}$ was sufficiently high temperature to induce changes in the inner structure of BPL carbon, resulting in pore opening.

As shown in Figure 5, impregnation temperature has a strong effect on the pore size distribution. When impregnation temperature decreased from 600 to $250{ }^{\circ} \mathrm{C}$, the portion of pores in the 40 to 100 è region also decreased. It is postulated that this difference in pore size distribution among BPL-S carbons is a direct result of impregnation temperature and sulfur loading. First, the amount of sulfur attached to the carbon increased as the impregnation temperature decreased. As a result, more pores will be filled for BPL-S-4/1-250 carbon. The existing form of sulfur molecules is another important factor. At lower impregnation temperature, sulfur molecules are mainly in the form of rings or long linear chains. Although these molecules will have little steric hindrance for oversized pores, they may form barriers in the medium size pores. As these large sulfur molecules attach to the carbon surface, they tend to block the entrance of medium pore openings and form multi-layers to further reduce the surface area. On the contrary, at higher impregnation temperatures, smaller and shorter chain sulfur molecules are dominant. They can migrate easily along the carbon pores, resulting in a more uniform sulfur distribution. Thus, more medium size pores are available in the carbons prepared at high temperatures.

Figure 6 shows that SCR does not change the pore size distribution significantly. Since these carbons were prepared at same high temperature and their sulfur content was very close, the physical impact on pore size distribution is very similar.

TGA test was performed on UFP-4/1-600 and HGR. As shown in Figure 7, HGR lost significant amount of sulfur, while the sulfur loss for UFP-4/1-600 was negligible. This indicates that bonding between carbon and sulfur molecules in HGR was weaker than that in UFP-4/1-600. Loosely bonded sulfur tends to agglomerate during the column test, leading to deterioration in performance for mercury uptake (3).

\subsection{Oxygen effect on mercury uptake by BPL-S-4/1-600 carbon}

Current and previous studies (4) have shown that BPL-S-4/1-600 has the highest capacity for elemental mercury uptake. This carbon was selected to further investigate how the presence of different gases would influence the performance of sulfur-impregnated activated carbon adsorbents. In the flue gas of a coal-fired power plant, the concentration of oxygen is about $8 \%$ and it is the most important active gas which may affect the performance of activated carbon adsorbents. Thus oxygen was chosen as the first candidate to be studied.

As shown in Figure 8, oxygen concentrations varied from $0 \%$ to $9 \%$ in the carrier gas studied for mercury uptake. When the $\mathrm{O}_{2}$ concentration was $3 \%$, small increase in mercury uptake by BPL-S4/1-600 was observed. The performance of BPL-S-4/1-600 was further improved when the $\mathrm{O}_{2}$ concentration increased from $3 \%(2400 \mu \mathrm{g} \mathrm{Hg} / \mathrm{g}$ carbon ) to $6 \%(2580 \mu \mathrm{g} \mathrm{Hg} / \mathrm{g}$ carbon $)$ and $9 \%$ (2990 $\mu \mathrm{g} \mathrm{Hg/g} \mathrm{carbon).}$

Prior to analyzing the effect of oxygen on the performance of BPL-S-4/1-600, the possibility of homogeneous reaction between oxygen and mercury was studied. The experimental setup was the 
same as for the breakthrough test. The only difference was that the fixed-bed column was empty instead of containing activated carbon. Identical conditions were established for this test: flow rate of $\mathrm{N}_{2}$ was $1.0 \mathrm{~L} / \mathrm{min}$; influent mercury concentration of $55 \mu \mathrm{g} / \mathrm{m}^{3}$ was monitored by AAS; oven temperature was $140{ }^{\circ} \mathrm{C}$. After that, a gas stream comprised of $10 \% \mathrm{O}_{2}$ and $90 \% \mathrm{~N}_{2}$ was used as the carrier gas and the effluent concentration was continuously monitored by AAS for 3 days. During this time period, the AAS showed that the effluent elemental mercury concentration was still $55 \mu \mathrm{g} / \mathrm{m}^{3}$ which indicates that no homogeneous gas phase reaction between mercury and oxygen occurred. The result of this control experiment was in agreement with other researchers' conclusions (5).

Oxygen is chemisorbed readily by activated carbons, and carbon-oxygen complexes are usually important in determining the surface reactions and surface behavior of the carbons (6). Therefore, it is necessary to study the possibility of forming carbon-oxygen complexes during the column run and their impact on mercury removal.

To study the formation of carbon-oxygen complexes upon exposure to oxygen, a ceramic boat containing 2.5 grams of BPL-S-4/1-600 was placed into a quartz tube and air was introduced into the tube at $1.0 \mathrm{~L} / \mathrm{min}$ and $140{ }^{\circ} \mathrm{C}$ for 7 days. After treatment with air, the acidic surface functional group content (carbon-oxygen complexes) of the carbon was determined using the titration with $\mathrm{NaOH}$ according to procedure described by Tessmer et al. (7) and was compared to the acidic functional group content of the virgin BPL-S-4/1-600 carbon. Table 2 summarizes the results of this test. From this table, it is clear that carbon-oxygen complexes have been formed when BPL-S carbon was exposed to oxygen.

Table 2. Titration of Different BPL-S-4/1-600 Samples

\begin{tabular}{|c|c|c|}
\hline Carbon Type & Acid used, $\mathrm{ml}$ & $\begin{array}{c}\text { Total acidic surface } \\
\text { functional group, } \mu \mathrm{eq} / \mathrm{g}\end{array}$ \\
\hline BPL-S-4/1-600 & 3.20 & 150 \\
\hline BPL-S-4/1-600 (air treated) & 2.25 & 625 \\
\hline
\end{tabular}

Column test was carried out in order to see if the changes of surface structure of carbon would alter the mercury removal capacity for the BPL-S carbon. The result was plotted in Figure 9. The air treated BPL-S-4/1-600 had the same mercury removal capacity when compared to the normal fresh BPL-S-4/1-600. Therefore, the improved performance of BPL-S carbons observed in the presence of oxygen in the feed stream is the result of the reaction between $\mathrm{Hg}$ and $\mathrm{O}_{2}$ that was catalyzed by the carbon surface.

Sulfur content of the air treated BPL-S-4/1-600 was measured by Sulfur Analyzer. Before the carbon was treated with air, the fresh BPL-S-4/1-600 had 10.04\% of sulfur. After the pretreatment procedure, the sulfur content was $9.17 \%$. The sulfur loss was about $1 \%$ for the BPL-S carbon. In our previous study (4), TGA results showed that BPL-S-4/1-600 lost 1\% of its total weight at elevated temperature $\left(40\right.$ to $\left.400{ }^{\circ} \mathrm{C}\right)$ within 3 hours. The same amount of weight loss for these two different experiments supported our previous hypothesis that the weight loss during the TGA test was mainly sulfur loss. It also indicated that the bonding between sulfur and carbon was 
strong, and the sulfur loss was not significant. In the TGA test, $100 \%$ pure argon was used as carrier gas. It could be postulated that sulfur should leave the carbon in elemental form under this inert environment. As for the air pre-treatment process, the reaction between sulfur and oxygen might have occurred. If $\mathrm{SO}_{2}$ was formed under this condition, its concentration in the gas stream could be estimated as follows:

Initial sulfur content in $100 \mathrm{mg}$ BPL-S-4/1-600, $\mathrm{S}_{\mathrm{o}}=10.04 \mathrm{mg}$

Final sulfur content in $100 \mathrm{mg}$ BPL-S-4/1-600, $\mathrm{S}_{\mathrm{f}}=9.17 \mathrm{mg}$

Sulfur loss $\Delta \mathrm{S}=\mathrm{S}_{\mathrm{o}}-\mathrm{S}_{\mathrm{f}}=0.87 \mathrm{mg} \approx 1 \mathrm{mg}$

Sulfur loss rate $\mathrm{r}=\Delta \mathrm{S} / \Delta \mathrm{T}=1 \mathrm{mg} / 7$ days $=9.92 \times 10^{-5} \mathrm{mg} / \mathrm{min}$

$$
\begin{aligned}
& \approx 1 \times 10^{-4} \mathrm{mg} / \mathrm{min} \\
& =3.1 \times 10^{-6} \mathrm{mmole} / \mathrm{min}
\end{aligned}
$$

If all the elemental sulfur was converted into $\mathrm{SO}_{2}$, the $\mathrm{SO}_{2}$ generation rate would be $3.1 \times 10^{-6}$ mmole/min. Applying the perfect gas law, at 1 atm and $298 \mathrm{~K}$, the volume of $\mathrm{SO}_{2}$ generated per minute is $7.6 \times 10^{-8} \mathrm{~L}$. Since the flow rate of the carrier gas was $1.0 \mathrm{~L} / \mathrm{min}$, the concentration of $\mathrm{SO}_{2}$ in the carrier gas would be $0.076 \mathrm{ppm}$.

In coal-fired power plants, the $\mathrm{SO}_{2}$ concentration in the flue gas is about $100-3000$ ppm (8). Apparently, even if $\mathrm{SO}_{2}$ was generated when oxygen/nitrogen mixture was used as carrier gas, the concentration of $\mathrm{SO}_{2}$ would be extremely low. It is postulated that $\mathrm{SO}_{2}$ effect is negligible. However, the impact of higher $\mathrm{SO}_{2}$ concentrations in flue gas will need to be thoroughly evaluated in this study.

\section{CONCLUSIONS}

Novel sulfur-impregnated adsorbents for vapor phase mercury removal have been designed and developed in this study, and their performance for mercury uptake was compared to several other mercury sorbents. The sulfur impregnation method which was developed in this study showed a great promise towards developing adequate mercury sorbent for use in coal-fired power plants.

SCR was the main control parameter investigated in this part of study. As the SCR was changed by a factor of 8 (from 4:1 to 1:2), the actual sulfur content of BPL-S carbons only varied by $30 \%$. Due to the fact that the total number of active sulfur atoms was reduced as the SCR decreased, the mercury uptake capacity was also diminished.

BET specific surface area also influenced the capacity of these new sorbents for mercury uptake. At high impregnation temperature, the amount of sulfur attached to the carbon was relatively small, but sulfur was more uniformly distributed on the carbon surface. Therefore, BPL-S carbons prepared at higher impregnation temperature $\left(600{ }^{\circ} \mathrm{C}\right)$ had larger surface area than other sorbents.

Pore size distribution study for BPL-S carbons also indicated that micro structure of the sorbents can affect the mercury removal efficiency. Study of virgin BPL carbon demonstrated that high 
heating temperature can change the inner structure of carbons and increase the pore openings. As a result, the portion of larger pores of BPL-S carbons increased as the impregnation temperature was elevated from $250{ }^{\circ} \mathrm{C}$ to $600{ }^{\circ} \mathrm{C}$. On the other hand, varying SCR at high impregnation temperature did not affect the pore size distribution. Similar to the effect of surface area, larger pores facilitate mercury uptake process by reducing the diffusion mass transfer resistance. Consequently, the performance of BPL-S carbons prepared at higher temperatures was improved compare to those prepared at lower temperatures.

Oxygen was introduced into the carrier gas stream to simulate the flue gas condition. Mercury uptake capacity was significantly improved when oxygen concentration was higher than $3 \%$. Oxygen would not react with mercury without the presence of activated carbon. Oxygen can form carbon-oxygen complexes on the carbon surface and alter the functional groups of the surface structure. However, this change had no direct impact on the performance of mercury uptake by BPL-S-4/1-600. Formation of mercury oxide $(\mathrm{HgO})$ was the major reason for the enhanced performance of BPL-S-4/1-600 carbon. Activated carbon might act as a catalyst to facilitate the mercury and oxygen reaction. BPL-S-4/1-600 lost small amount of sulfur during the column run. The lost sulfur might be in elemental $(\mathrm{S})$ or oxidized $\left(\mathrm{SO}_{2}\right)$ form. In either case, the vapor phase concentration of $\mathrm{S}$ or $\mathrm{SO}_{2}$ would be extremely low and their impact would be negligible.

The pending tasks of our research include continuation of the column tests using other gases such as $\mathrm{CO}_{2}, \mathrm{SO}_{2}$ and $\mathrm{NO}_{\mathrm{x}}$ to further simulate the flue gas composition. In addition, virgin BPL carbon will be impregnated with other compounds such as chloride and chelating agents to evaluate the mercury removal efficiency of carbons when these chemicals are present. Varying proportions of flow rates, carbon masses, and carbon sizes will be used to determine whether the results can be scaled up to predict the performance of full-scale adsorbers.

\section{REFERENCES}

1. Ferens, M. C.; A Review of the Physiological Impact of Mercuries; U. S. EPA. U. S. Government Printing Office: Washington, D. C. 1974; EPA-660/3-73-022.

2. Young, B. C.; Miller, S. J.; Laudal, D. L.; Presented at the 1994 Pittsburgh Coal Conference, Pittsburgh, PA, September, 1994.

3. Liu, W.; Korpiel, J. A.; Vidic, R. D.; Paper 97-WA72A.02. The Air \& Waste Management Association's 90th Annual Meeting \& Exhibition, June 8-13, 1997, Toronto, Ontario, Canada.

4. Vidic, R. D., DOE Semi-Annual Report, 96212R01.DOC.

5. Hall, B.; Schager, P.; Weesman, J.; Chemosphere, Vol. 30, No. 4, 1995, 611-627.

6. Walker, P. L. ed.; Chemistry and Physics of Carbon Volume 6, New York, Marcel Dekker Inc., 1970, pp 264-282.

7. Tessmer, C. H.; Vidic, R. D.; Uranowski, L. J.; Environ. Sci. \& Tech., Vol. 31, 1997, 18721878.

8. Chang, R.; Offen, G.; Power Engineering, Vol. 99, No. 11, 1995, 51-57. 


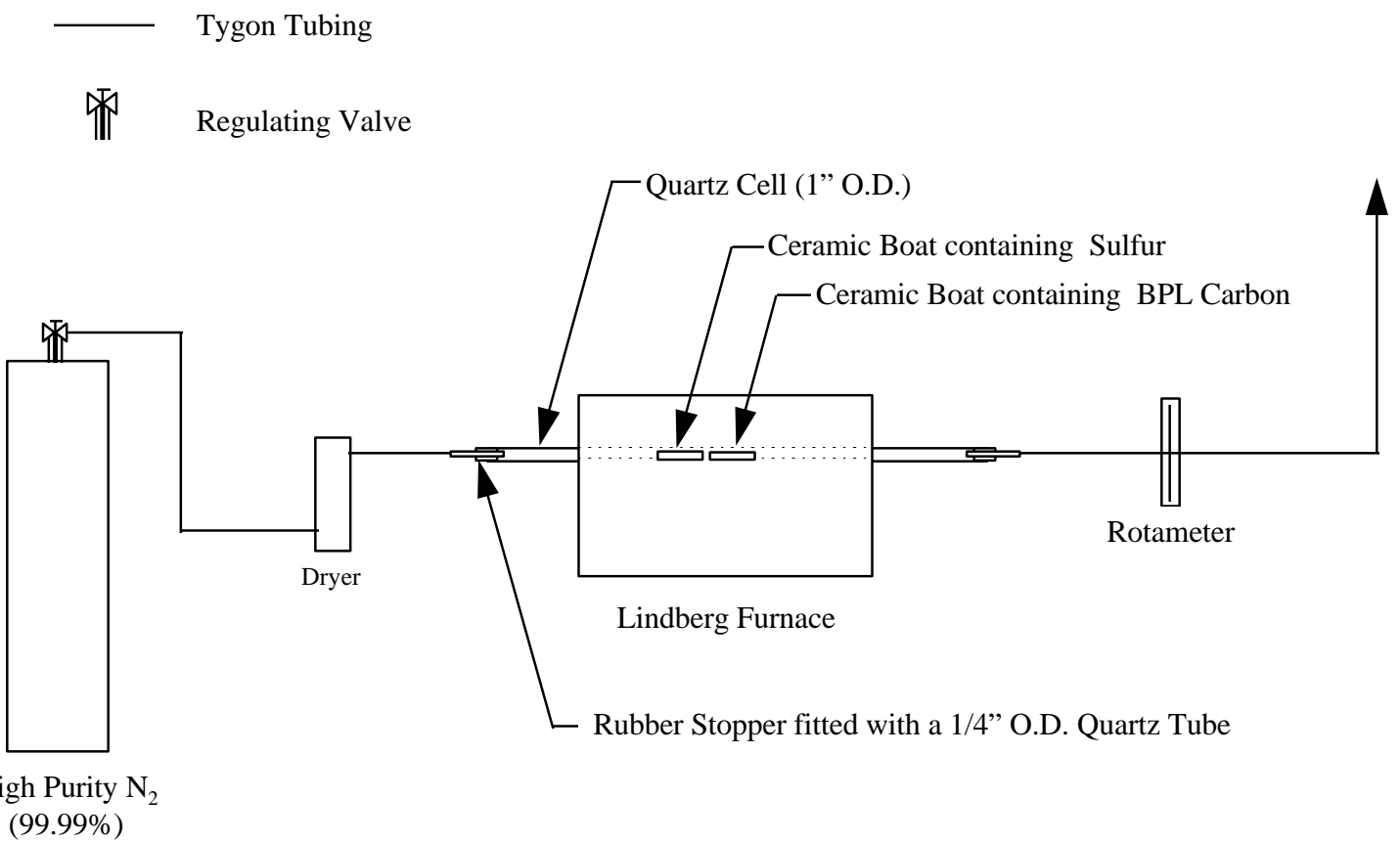

Figure 1. Setup of Impregnation System 


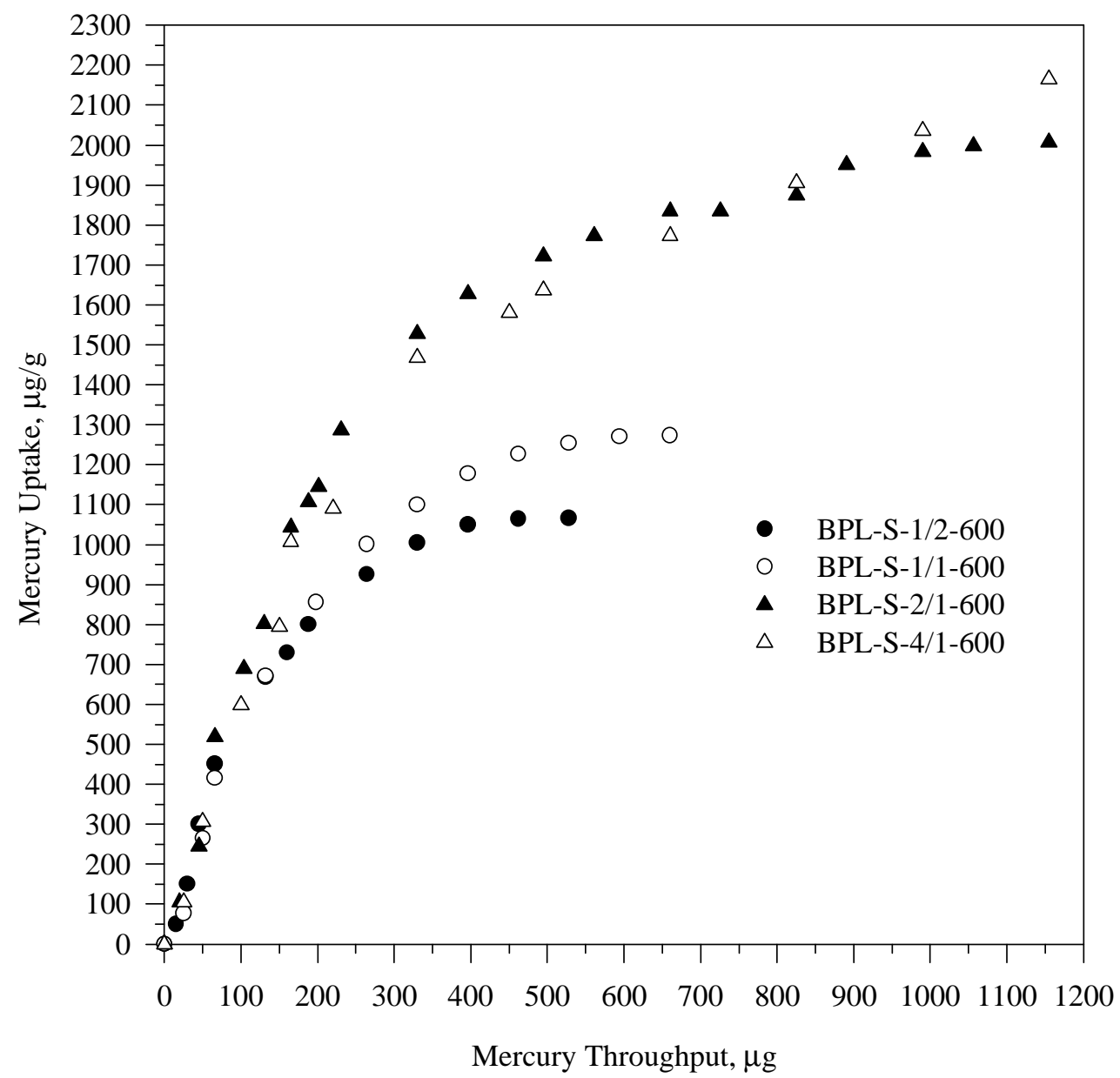

Figure 2. Mercury Uptake by BPL-S-600 Series with Different SCR 


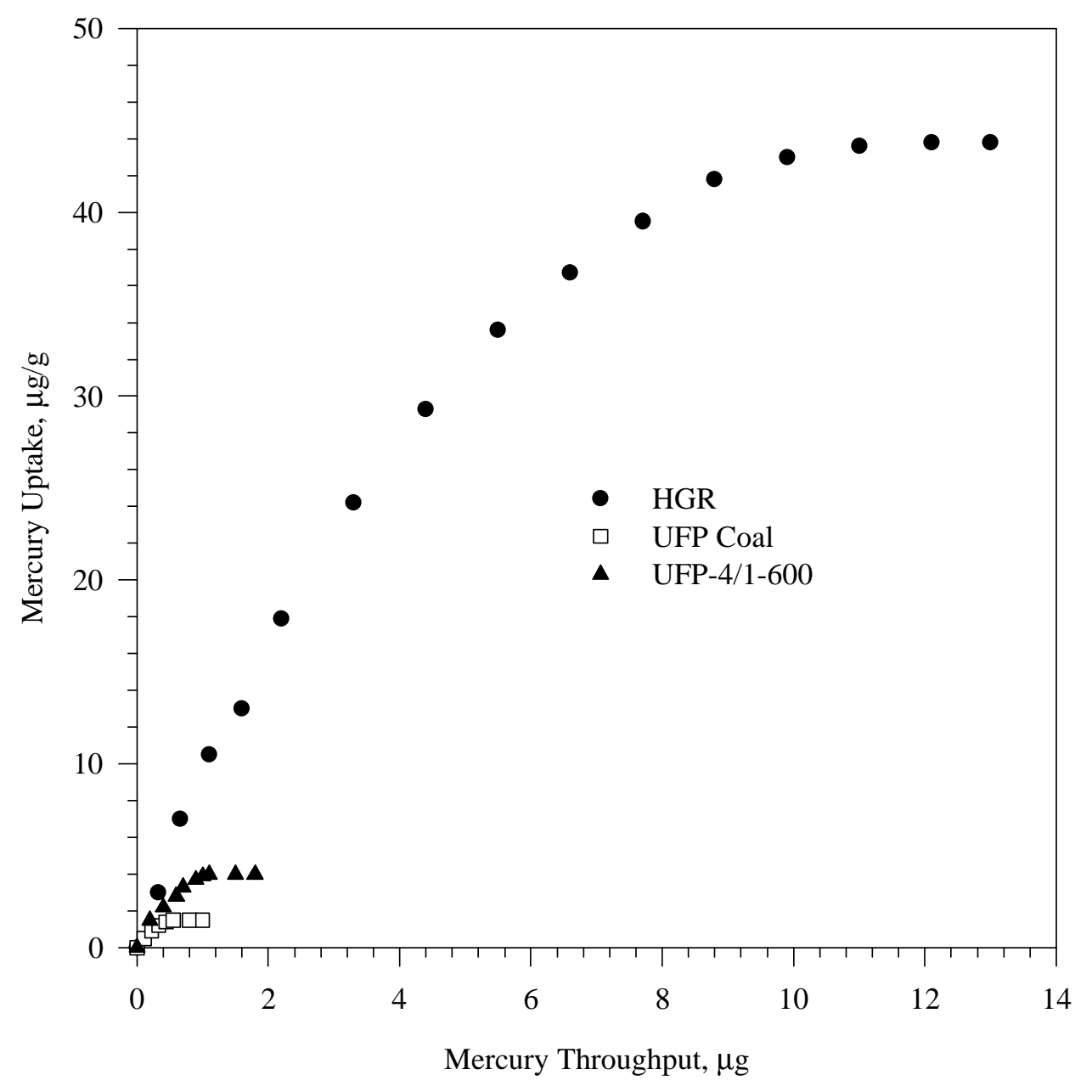

Figure 3. Mercury Uptake by UFP Coal and HGR Carbon 


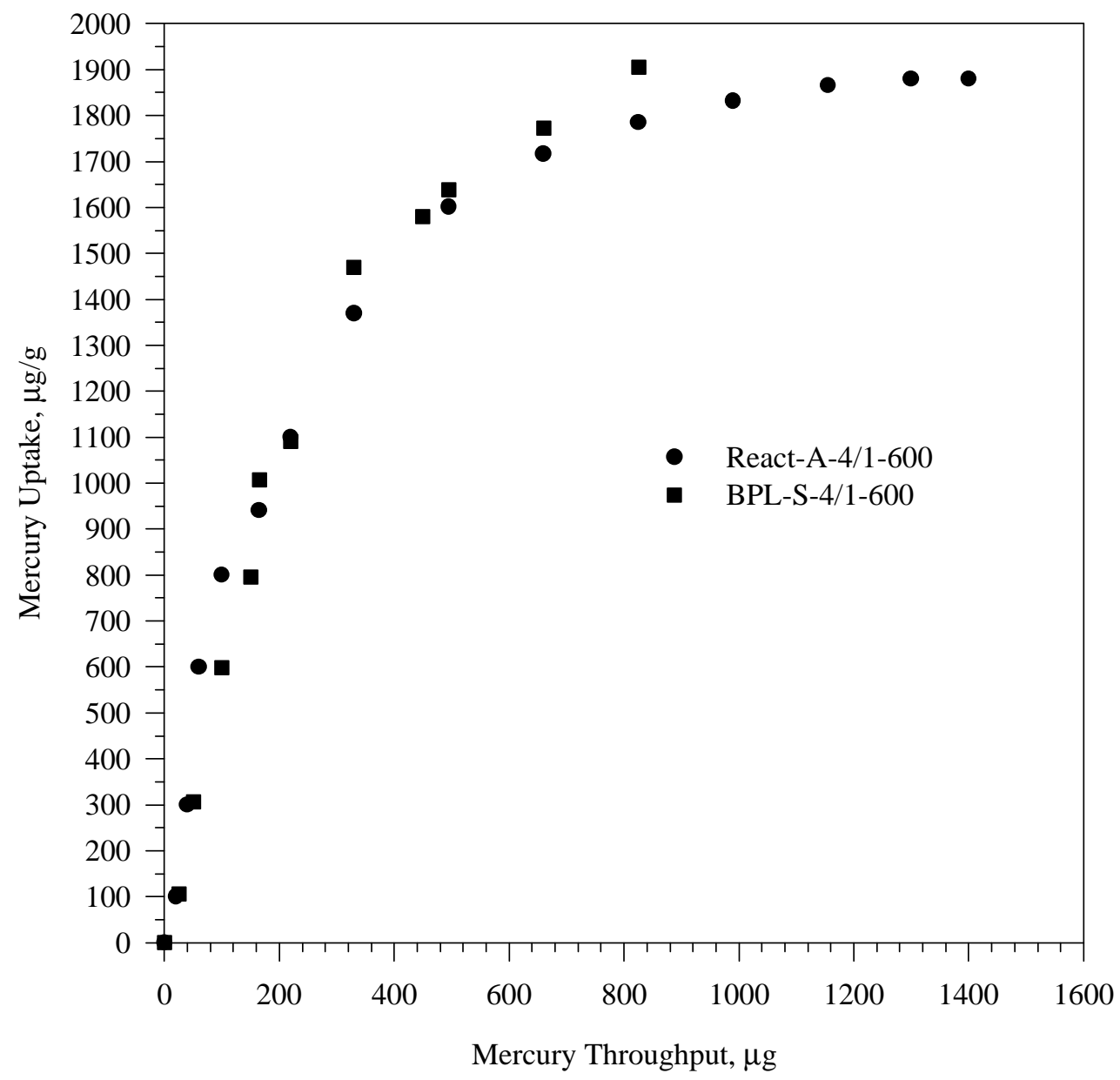

Figure 4. Mercury Uptake by Sulfur Impregnated Virgin and Reactivated Carbons 


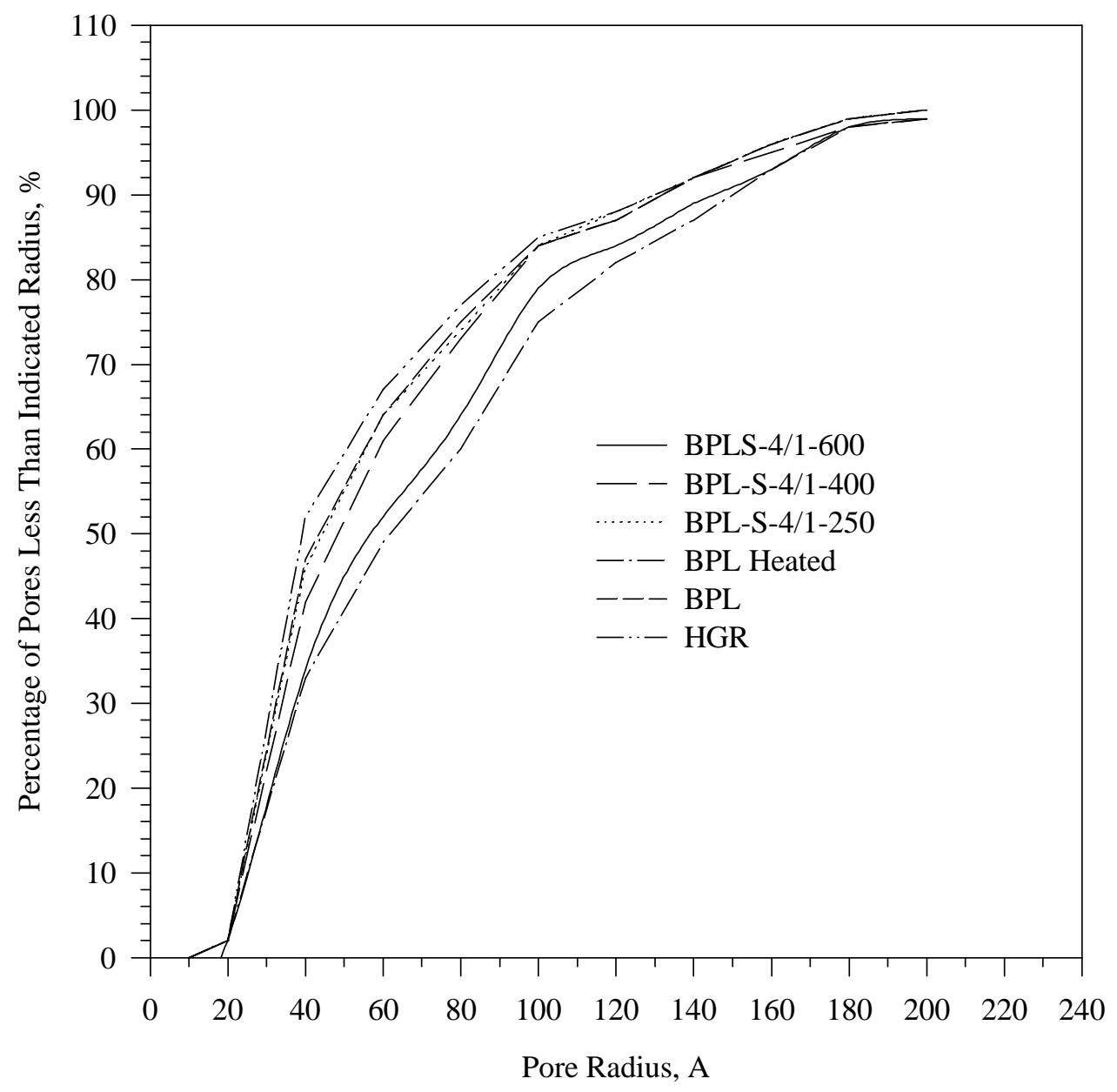

Figure 5. Pore Size Distribution For BPL-S-600, BPL and HGR Carbons 


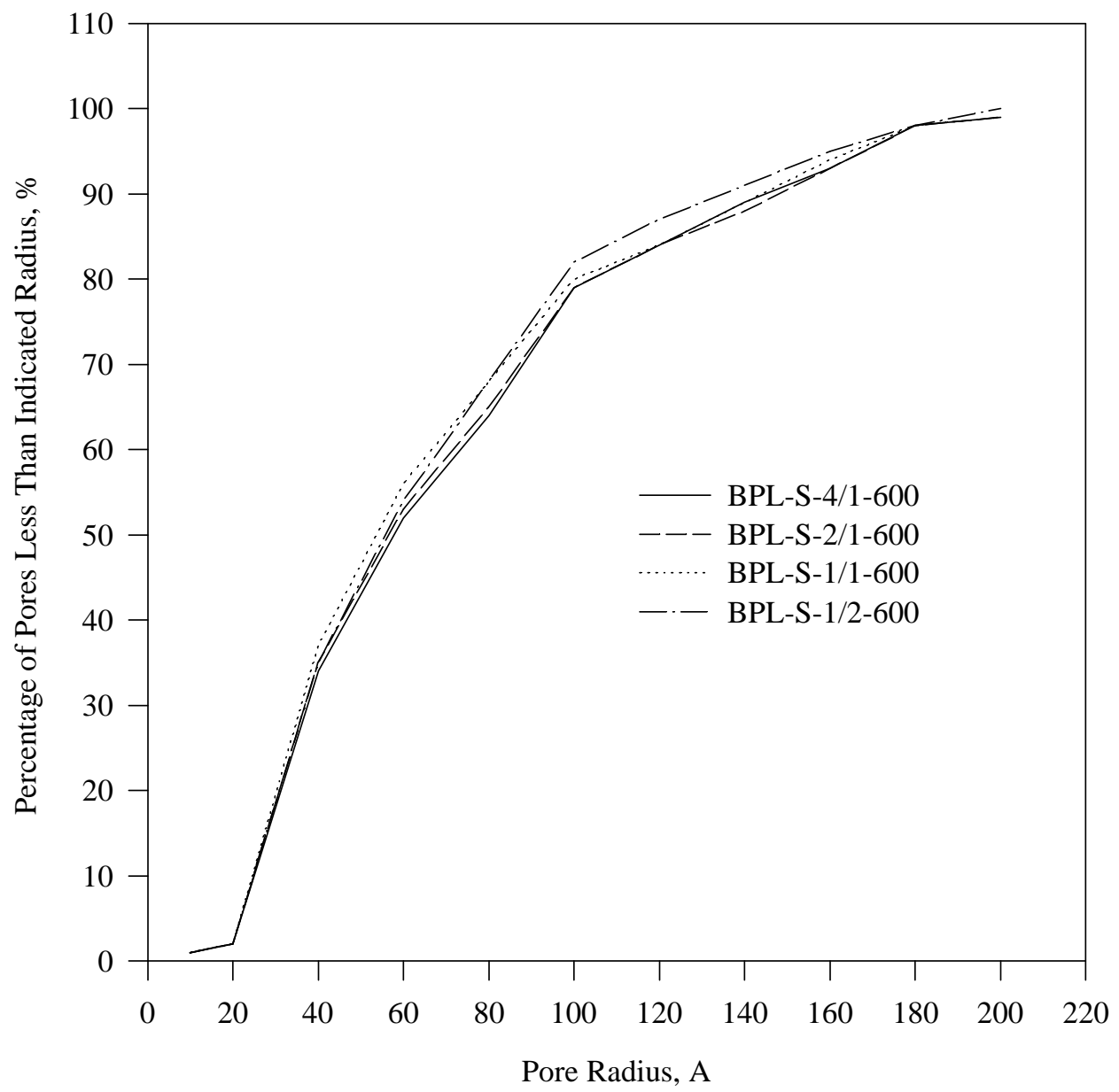

Figure 6. Pore Size Distribution for BPL-S with Different SCRs 


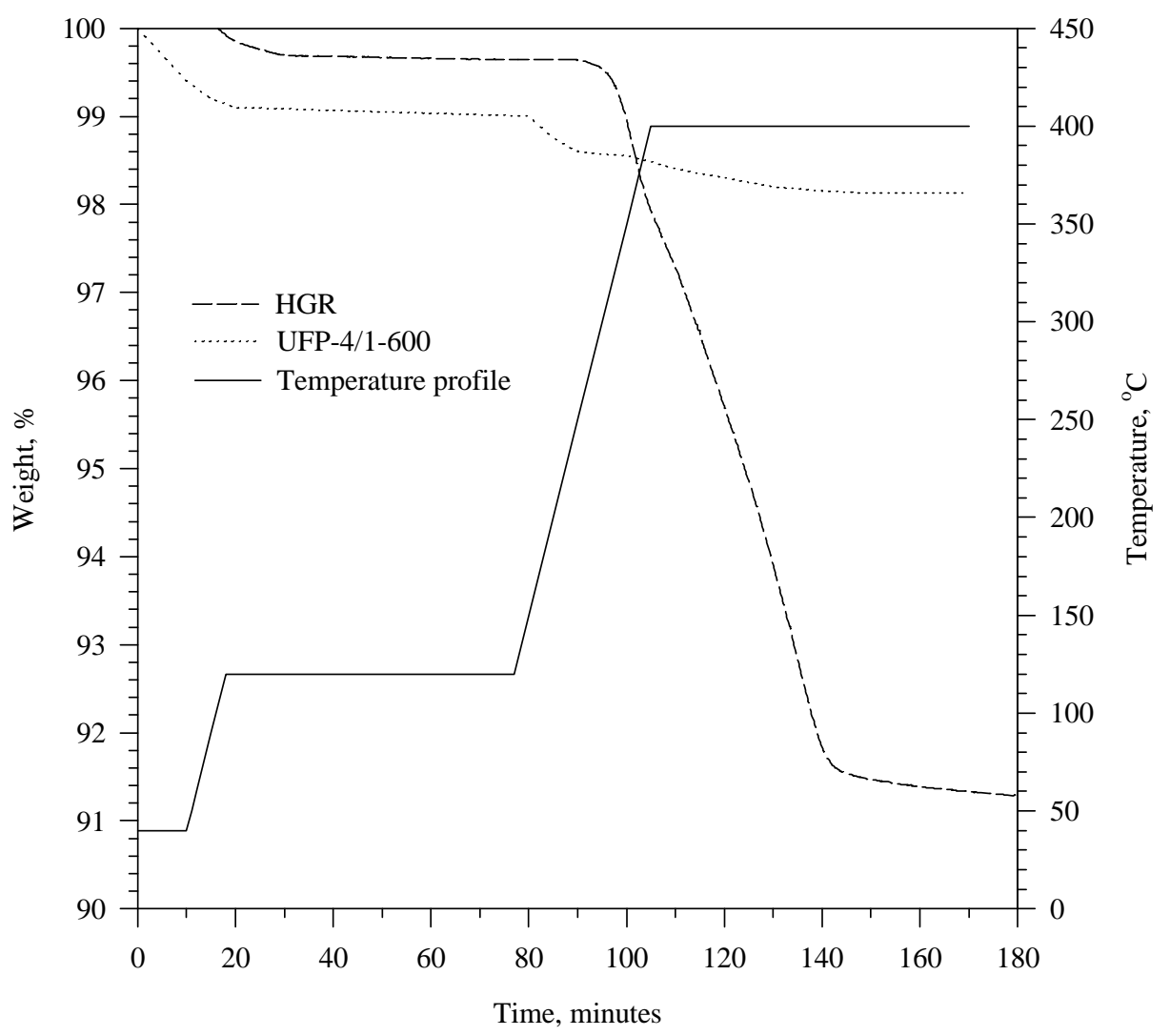

Figure 7. TGA Analyses for UFP Coal and HGR Carbon 


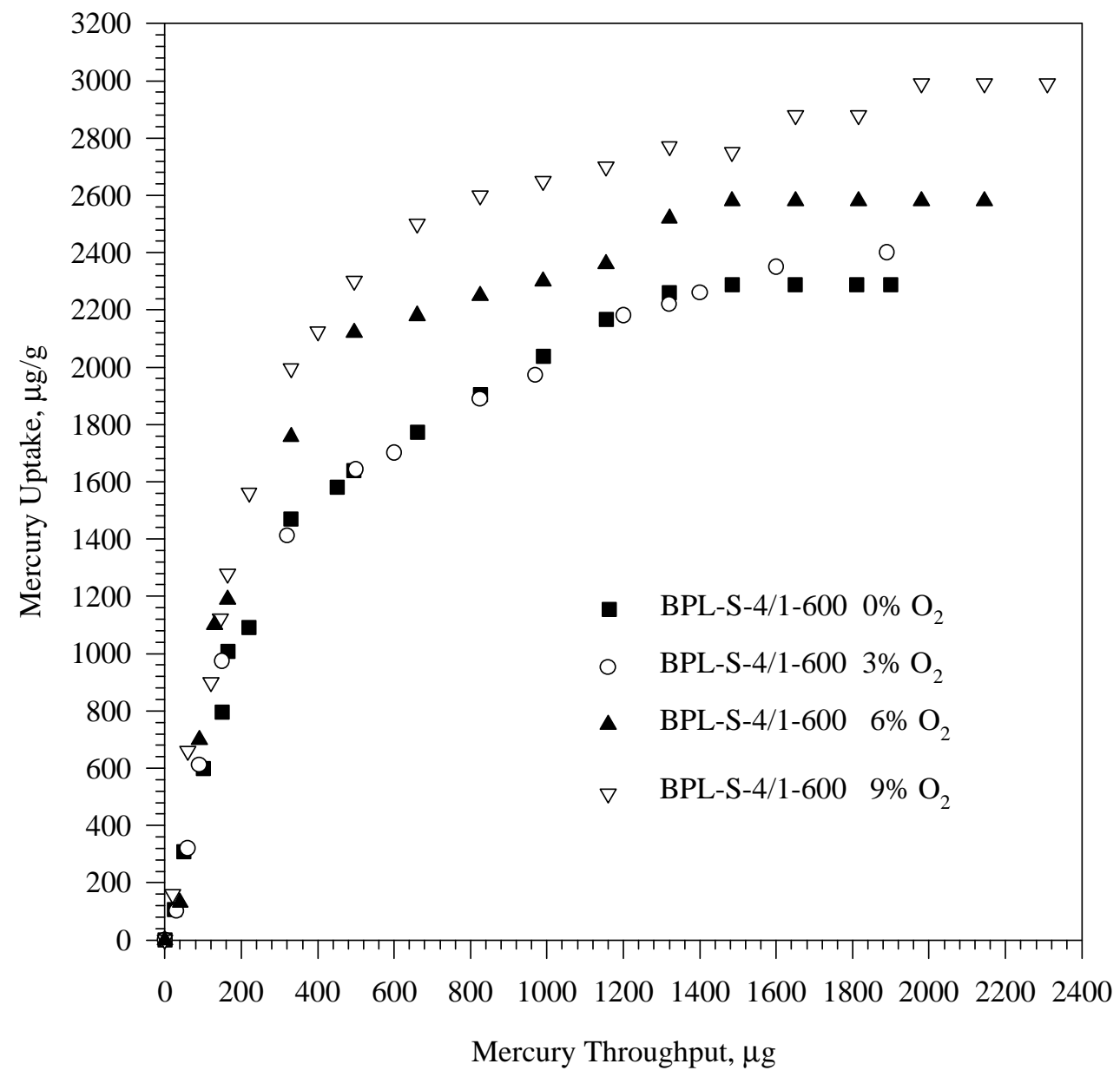

Figure 8. Oxygen Effect on Mercury Uptake for BPL-S-4/1-600 


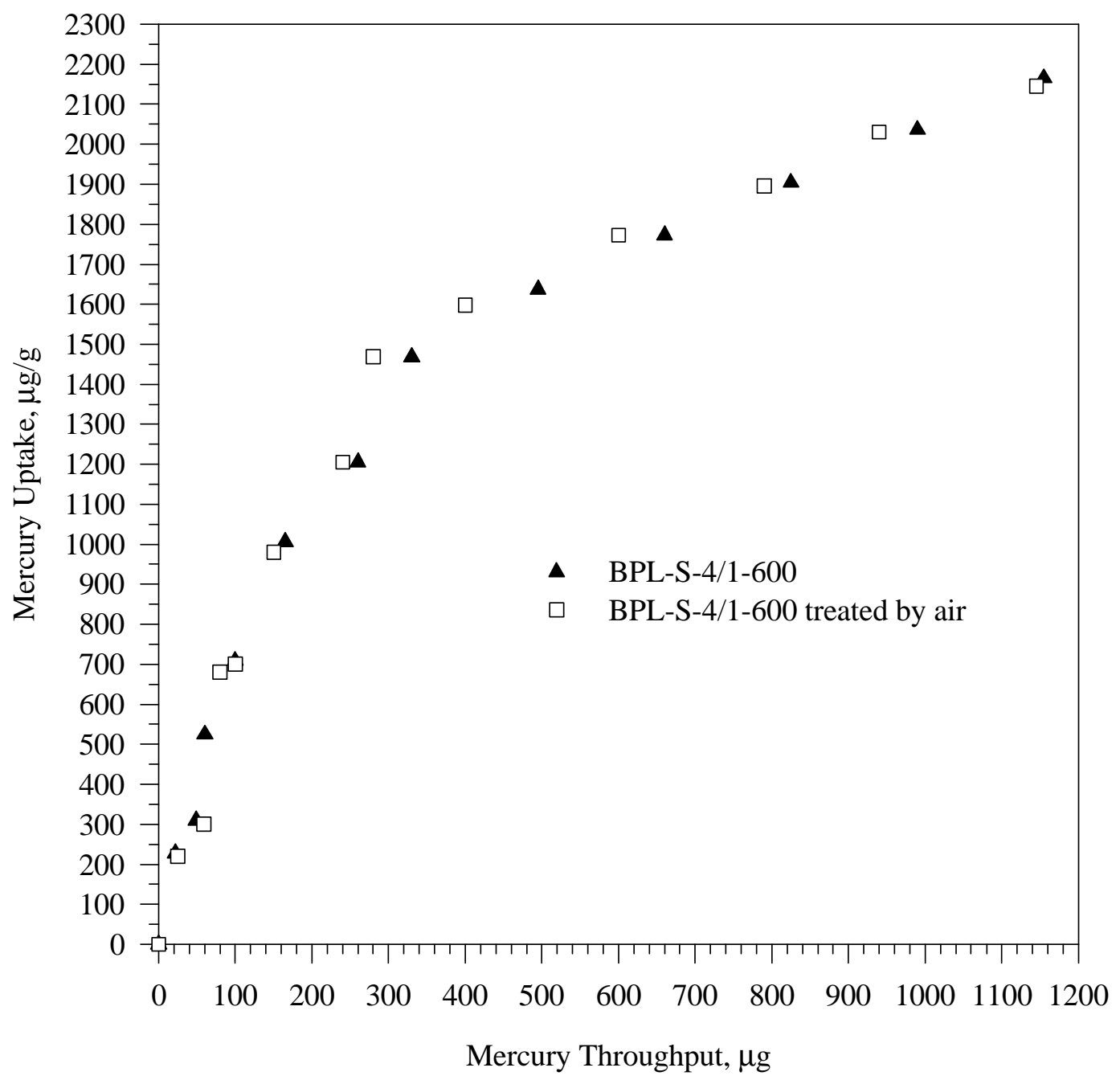

Figure 9. Comparison of Mercury Uptake between BPL-S-4/1-600 and Air Treated BPL-S-4/1600 